This article was downloaded by:[Pucci, Ida]

On: 22 February 2008

Access Details: [subscription number 790779750]

Publisher: Informa Healthcare

Informa Ltd Registered in England and Wales Registered Number: 1072954

Registered office: Mortimer House, 37-41 Mortimer Street, London W1T 3JH, UK

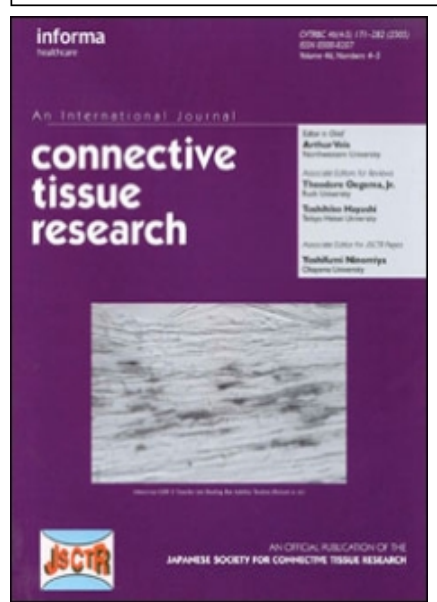

\title{
Connective Tissue Research
}

Publication details, including instructions for authors and subscription information: http://www.informaworld.com/smpp/title content=t713617769

Decorin Transfection Induces Proteomic and Phenotypic Modulation in Breast Cancer Cells 8701-BC

Ida Pucci-Minafra ${ }^{\text {ab }}$; Patrizia Cancemi ${ }^{\text {ab }}$; Gianluca Di Cara ${ }^{a}$; Luigi Minafra ${ }^{a}$; Salvatore Feo ${ }^{\mathrm{ab}}$; Antonella Forlino ${ }^{\mathrm{c}}$; M. Enrica Tira ${ }^{\mathrm{c}}$; Ruggero Tenni ${ }^{\mathrm{c}}$; Désirée Martini ${ }^{d}$; Alessandro Ruggeri ${ }^{d}$; Salvatore Minafra ${ }^{a b}$

a Dipartimento di Oncologia Sperimentale e Applicazioni Cliniche, University of Palermo, Palermo, Italy

b Centro di Oncobiologia Sperimentale, Ospedale "La Maddalena,", Palermo, Italy

c Dipartimento di Biochimica "A. Castellani", University of Pavia, Pavia, Italy

d Dipartimento di Scienze Anatomiche Umane e Fisiopatologia dell'Apparato Locomotore, University of Bologna, Bologna, Italy

Online Publication Date: 01 January 2008

To cite this Article: Pucci-Minafra, Ida, Cancemi, Patrizia, Cara, Gianluca Di, Minafra, Luigi, Feo, Salvatore, Forlino, Antonella, Tira, M. Enrica, Tenni, Ruggero, Martini, Désirée, Ruggeri, Alessandro and Minafra, Salvatore (2008) 'Decorin Transfection Induces Proteomic and Phenotypic Modulation in Breast Cancer Cells 8701-BC', Connective Tissue Research, 49:1, 30 - 41

To link to this article: DOI: $10.1080 / 03008200701820443$

URL: http://dx.doi.org/10.1080/03008200701820443

\section{PLEASE SCROLL DOWN FOR ARTICLE}

\section{Full terms and conditions of use: http://www.informaworld.com/terms-and-conditions-of-access.pdf}

This article maybe used for research, teaching and private study purposes. Any substantial or systematic reproduction, re-distribution, re-selling, loan or sub-licensing, systematic supply or distribution in any form to anyone is expressly forbidden.

The publisher does not give any warranty express or implied or make any representation that the contents will be complete or accurate or up to date. The accuracy of any instructions, formulae and drug doses should be independently verified with primary sources. The publisher shall not be liable for any loss, actions, claims, proceedings, demand or costs or damages whatsoever or howsoever caused arising directly or indirectly in connection with or arising out of the use of this material. 


\title{
Decorin Transfection Induces Proteomic and Phenotypic Modulation in Breast Cancer Cells 8701-BC
}

\author{
Ida Pucci-Minafra and Patrizia Cancemi \\ Dipartimento di Oncologia Sperimentale e Applicazioni Cliniche, University of Palermo, \\ and Centro di Oncobiologia Sperimentale, Ospedale "La Maddalena," Palermo, Italy
}

Gianluca Di Cara and Luigi Minafra

Dipartimento di Oncologia Sperimentale e Applicazioni Cliniche, University of Palermo, Palermo, Italy

\begin{abstract}
Salvatore Feo
Dipartimento di Oncologia Sperimentale e Applicazioni Cliniche, University of Palermo, and Centro di Oncobiologia Sperimentale, Ospedale "La Maddalena," Palermo, Italy
\end{abstract}

\author{
Antonella Forlino, M. Enrica Tira, and Ruggero Tenni \\ Dipartimento di Biochimica “A. Castellani”, University of Pavia, Pavia, Italy
}

\author{
Désirée Martini and Alessandro Ruggeri \\ Dipartimento di Scienze Anatomiche Umane e Fisiopatologia dell' Apparato Locomotore, \\ University of Bologna, Bologna, Italy
}

\section{Salvatore Minafra}

Dipartimento di Oncologia Sperimentale e Applicazioni Cliniche,University of Palermo, and Centro di Oncobiologia Sperimentale, Ospedale “La Maddalena," Palermo, Italy

\begin{abstract}
Decorin is a prototype member of the small leucine-rich proteoglycan family widely distributed in the extracellular matrices of many connective tissues, where it has been shown to play multiple important roles in the matrix assembly process, as well as in some cellular activities. A major interest for decorin function concerns its role in tumorigenesis, as growth-inhibitor of different neoplastic cells, and potential antimetastatic agent. The aim of our research was to investigate wide-ranged effects of transgenic decorin on breast cancer cells. To this purpose we utilized the well-characterized 8701-BC cell line, isolated from a ductal infiltrating carcinoma of the breast, and two derived decorin-transfected clones, respectively, synthesizing full decorin proteoglycan or its protein core. The responses to the ectopic decorin production were examined by studying morphological changes, cell proliferation rates, and proteome modulation. The results revealed new important antioncogenic potentialities, likely exerted by decorin through a variety of distinct biochemical pathways. Major effects included the downregulation of several
\end{abstract}

Received 26 June 2007; revised 3 September 2007; accepted 20 September 2007.

Address correspondence to Prof. Ida Pucci-Minafra, Dipartimento di Oncologia Sperimentale e Applicazioni Cliniche, Via San Lorenzo Colli 31290146 Palermo, Italy. E-mail: idapucci@unipa.it potential breast cancer biomarkers, the reduction of membrane ruffling, and the increase of cell-cell adhesiveness. These results disclose original aspects related to the reversion of malignant traits of a prototype of breast cancer cells induced by decorin. They also raise additional interest for the postulated clinical application of decorin.

Keywords Decorin, Breast cancer, Proteomics

\section{INTRODUCTION}

Recent advances in cancer research have reinforced the concept that while initial stages of cancer are due to genetic alterations, its progression toward higher levels of malignancy is mainly sustained by epigenetic events, induced by signals emanating from the host stroma. Indeed, the latter, rather than being a passive scaffold, is a dynamic microenvironment rich with potentially informative activities. The instructive role of extracellular territories during embryogenesis and its reoccurrence in cancer has been postulated or demonstrated by several authors [1-4]. Collagen is the major component of the extracellular matrix: its role on shaping stromal architecture and cell-matrix communications in cancer has been described 
by several researchers [5-8]. In addition, the proteoglycan superfamily has been shown to perform or support a variety of extracellular functions [9].

Decorin, a prototype member of the small leucine-rich proteoglycan family (SLRP), is widely distributed in many connective tissues $[10,11]$, where it plays a structural role because of its ability to bind collagens [12-16] and other extracellular proteins [17-19]. Moreover, decorin is able to interact with cells of different origin through a proposed mechanism involving the epidermal growth factor receptor (s) and a functional p21 [20, 21]. Through the latter pathway decorin has been shown to exert a growth-suppressive effect, to a different extent, in various tumor cell lines [22-24].

In spite of the large number of studies on the effects of decorin as a putative antioncogenic factor, its wide-ranging consequence on protein expression profile has not been investigated yet.

Due to these considerations, we aimed at investigating the in vitro effects of decorin produced by a transgene on the proteomic profile of breast cancer cells. For this study we utilized the breast cancer cell line 8701-BC, well characterized also for the proteomic profile [25-28], and two derived decorin-transfected clones, respectively, synthesizing full decorin proteoglycan (DEC-C2 clone) or its protein core (DEC-C3 clone). The responses to the ectopic decorin production were examined by monitoring cell proliferation rates, morphological changes, and proteomic modulation. Our results illustrate for the first time that ectopic decorin not only exerts a growth-retarding effect on breast cancer cells, but also induces notable proteomic modulation and cellular responses. The most significant are the reversion of cell surface perturbation, decreased expression levels of glycolytic enzymes, as well as of other candidate biomarkers for breast cancer progression.

\section{MATERIALS AND METHODS}

\section{Cell Culture}

The breast cancer cell line 8701-BC, derived from a ductal infiltrating carcinoma, was described previously [25]. Cells were grown in RPMI 1640 medium (Invitrogen), with $10 \%(\mathrm{v} / \mathrm{v})$ fetal calf serum (FCS, Invitrogen), and $1 \%$ antibiotics (100 U penicillin and $100 \mu \mathrm{g}$ streptomycin $/ \mathrm{ml}$ ) and cultured at $37^{\circ} \mathrm{C}$ in a $5 \% \mathrm{CO}_{2}$ atmosphere.

\section{Decorin Expression Vector and Transfection}

A decorin cDNA fragment corresponding to nt 172 to 1161 (decorin sequence MN001920) was isolated by RT-PCR from human fibroblasts RNA with oligonucleotides containing $5^{\prime}$ overhang sequences with BamHI and XbaI restriction sites (forward-TTGGGATCCGATGAGGCTTCTGGGATAGG, reverse-TTGTCTAGATTACTTATAGTTTCC GAGTTG), and cloned into the BamHI/XbaI sites of the pcDNA4/HisMax expression vector (Invitrogen). To allow an efficient secretion of the recombinant proteins, a specific peptide signal from the V-J2-C region of the mouse Ig kappa-chain was then inserted

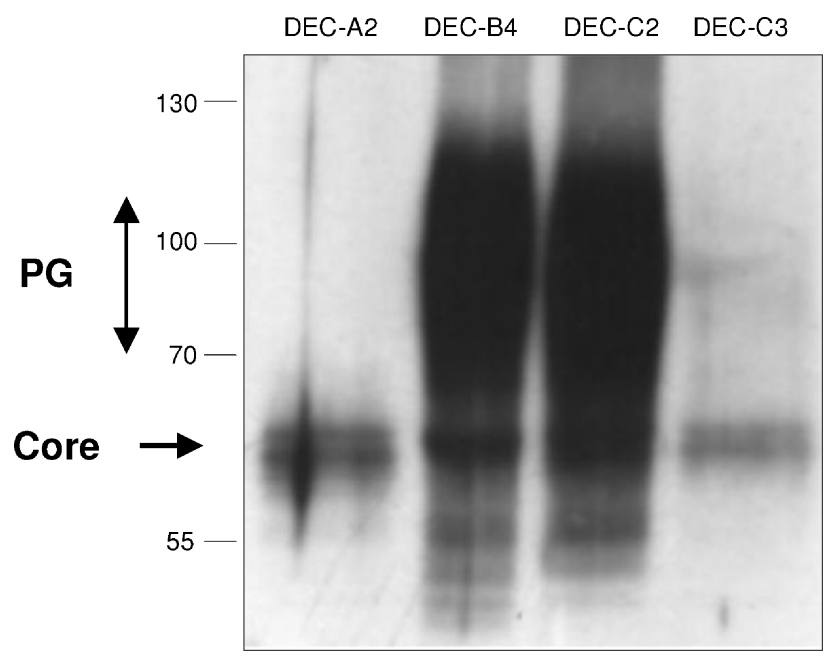

FIG. 1. Western blotting, using an anti-His tag antibody conjugated with horseradish peroxidase on secreted proteins of four independent decorintransfected clones. Proteins from culture media were precipitated by $15 \% \mathrm{TCA}$ (final) and electrophoresed on $8 \%$ SDS PAGE. The clones designated DEC-C2, expressing and secreting the full decorin proteoglycan (PG), and the clone designated DEC-C3, which express and secrete the protein core, were selected for this study.

between the start codon of the protein and the His-tag by cloning a 78 bp double stranded oligonucleotide into the NcoI site of the vector. In frame insertion and correct orientation of the cloned fragments were confirmed by nucleotide sequencing.

Exponentially growing 8701-BC cells were transfected using Lipofectamine Plus (Invitrogen) according to the manufacturer's instructions and maintained under selection for 14 days in RPMI-1640 medium supplied with $10 \%$ FCS and $0.4 \mathrm{mg} / \mathrm{ml}$ Zeocin. A reporter plasmid lacking decorin cDNA (mocktransfection) was used as negative control.

Several clones were isolated and studied for decorin expression. Two independent clones were selected for present studies, the clone designated DEC-C2, that expresses and secretes the full decorin proteoglycan, and the clone designated DEC-C3, that expresses and secretes the protein core (Figure 1).

\section{Cell Proliferation Assays}

Growth response of 8701-BC cells to ectopically expressed or exogenously supplied decorin was determined by a colorimetric MTS cell proliferation assay (Promega), according to the manufacturer's instructions. Cell proliferation was determined at 24-hr intervals throughout a 7-day period. Decorin used for the assays was extracted and purified from bovine tendon as described previously [29], and each kinetic evaluation was performed by supplementing the culture medium with three different concentrations of the purified protein: 5, 7.5 and $10 \mu \mathrm{g} / \mathrm{ml}$.

\section{Scanning Electron Microscopy}

At the established times the samples were processed for SEM observation. The plates were carefully rinsed with PBS 
to prevent detachment of cells from the glass. Cells were fixed with Karnowski solution (1.5\% glutaraldehyde, 1\% paraformaldehyde, $1 \%$ cacodylate buffer, $\mathrm{pH} 7.4$ ) for $10 \mathrm{~min}$. Plates with adhering cells were then rinsed three times with $0.1 \%$ cacodylate buffer, postfixed for $20 \mathrm{~min}$ with $1 \% \mathrm{OsO}_{4}$ in cacodylate buffer, dehydrated with ethanol, and finally dried with hexamethyldisilazane (Sigma) for $15 \mathrm{~min}$. Then the specimens were coated with $20 \mathrm{~nm}$-thick palladium-gold film and examined using a Philips SEM 515 at $15 \mathrm{kV}$.

\section{Two Dimensional Gel Electrophoresis}

Cells grown to confluence were deprived of serum and then lysed in RIPA buffer as previously described [27]. Protein concentration in the cellular extracts was determined by the Bradford method [30]. Proteins were solubilized in ISOT buffer (4\% CHAPS, $40 \mathrm{mM}$ Tris, $65 \mathrm{mM}$ DTE in $8 \mathrm{M}$ urea) and aliquots of $45 \mu \mathrm{g}$ (analytical gels) or $1.5 \mathrm{mg}$ (preparative gels) used for the electrophoretic separation. First dimension was performed with IPG strips $(18 \mathrm{~cm}$, nonlinear $\mathrm{pH}$ range 3.5 to 10 , Pharmacia); the 1D run was carried out by linearly increasing voltage from 200 to $3500 \mathrm{~V}$ during the first $3 \mathrm{hr}$, after which focusing was continued at $8000 \mathrm{~V}$ for $8 \mathrm{hr}$.

After the electrophoresis the IPG strips were equilibrated with a solution containing $6 \mathrm{M}$ urea, $30 \%$ glycerol, $2 \%$ SDS, $0.05 \mathrm{M}$ Tris-HCl, pH 6.8, and 2\% DTE for $12 \mathrm{~min}$ to resolubilize proteins and reduce disulfide bonds. The - $\mathrm{SH}$ groups were then blocked by substituting the DTE with $2.5 \%$ iodoacetamide in the equilibrating buffer. The focused proteins were then separated on 9-16\% linear gradient polyacrylamide gels (SDSPAGE) with a constant current of $40 \mathrm{~mA} / \mathrm{gel}$ at $10^{\circ} \mathrm{C}$. Gels were stained with ammoniacal silver nitrate, digitized using a computing densitometer, and processed with ImageMaster 2D platinum system (Amersham Biosciences). Absence of discernible residual serum proteins was monitored by $2 \mathrm{D}-\mathrm{IPG}$ of FCS.

\section{Protein Identification}

The protein identity was assessed by $\mathrm{N}$-terminal sequencing and by gel matching with reference maps previously obtained in our laboratory and available in the Expasy database (http://www.expasy.ch/world-2dpage/) where identification was performed by N-terminal microsequencing (Procise, 419 Applied Biosystems) and by MALDI-TOF (Voyager DE-PRO, Applied-Biosystems) as described [28, 31]. Matching validation relied on $\mathrm{N}$-terminal sequencing of five randomly selected protein spots, among the ones previously identified.

\section{Protein Spot Quantification}

Relative intensity of protein spots in the matched 2D gels from parental and transfected cells was determined by the densitometry algorithms of the Image Master software, normalizing the data to the sum of all spot volumes on gels $(\mathrm{Vol} \%)[32,33]$.
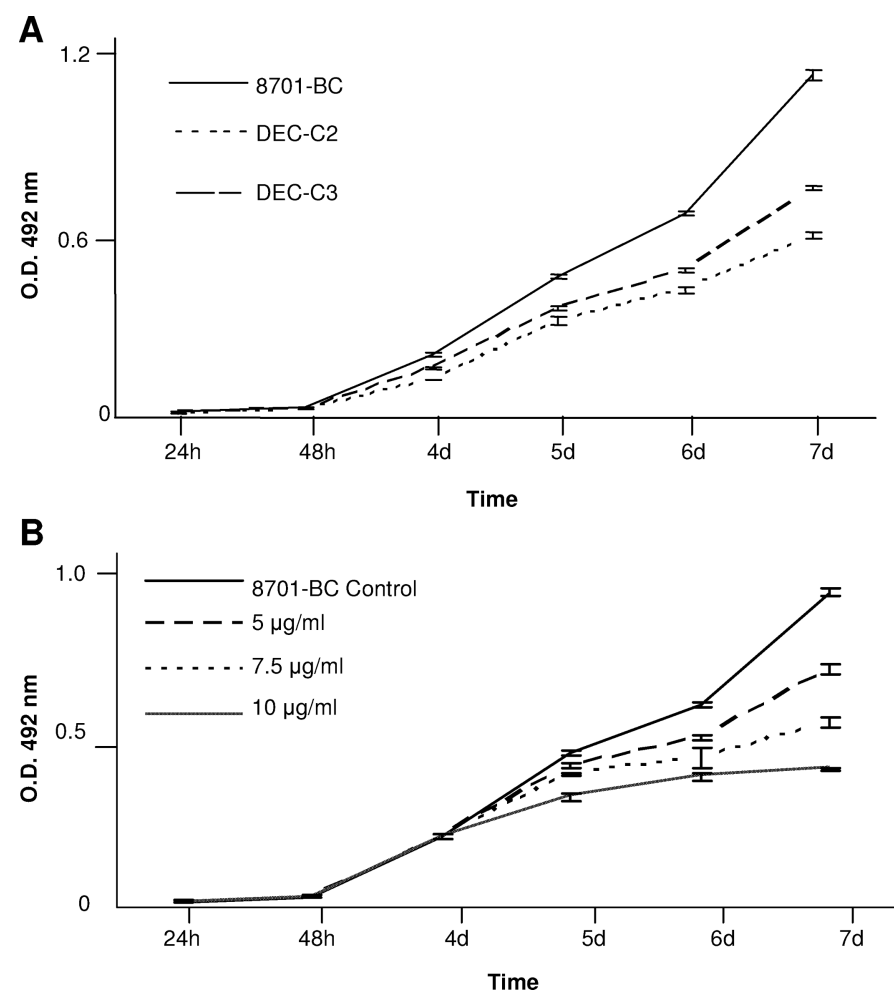

FIG. 2. (A) shows the growth rate of 8701-BC cell line and the two selected decorin-transfected clones, DEC-C2 and DEC-C3, by using the MTS colorimetric assay. (B) shows the growth curves of the 8701-BC control cells and of cells exposed to exogenous decorin from days 4 to 7 , at concentrations of $5,7.5$, and $10 \mu \mathrm{g} / \mathrm{ml}$ respectively, by using the MTS colorimetric assay. Each time point represents the mean of 4 replicates from two independent experiments ( $\pm \mathrm{SD})$.

\section{RESULTS}

\section{Ectopic and Exogenous Decorin and Cell Growth}

To investigate the effect of decorin, either the entire proteoglycan or its protein core, on the growth rate of our cellular system, we performed parallel proliferation assays on the two selected decorin-transfected clones, DEC-C2 and DEC-C3, and on the parental 8701-BC cell line, by using the MTS colorimetric assay as described in the previous section. Cell proliferation was determined at 24, 48 and $96 \mathrm{hr}, 5,6$ days and 7 days (Figure 2A). The retarding effect of ectopic decorin on cell growth of both DEC-C2 and DEC-C3 begins at 4 days from seeding. At 7 days the growth rate of the two clones is significantly reduced: the DEC-C2 shows a reduction of $\sim 50 \%$ with respect to the control cells, whereas the DEC-C3 displays a reduction of $33 \%$ versus the parental cell cultures. No differences were observed between parental 8701-BC and mock-transfected cells, thus excluding the occurrence of possible nonspecific effects caused by the vector transfection (data not shown).

To verify if the decreased growth rate could be mediated by cell surface receptorial apparatus, we repeated the proliferation assays by incubating the parental 8701-BC cells with increasing 
quantities of exogenous decorin. Figure 2B shows the growth curves of the parental cells and the curves of cells exposed to exogenous decorin from days 4 to 7 , at concentrations of $5,7.5$, and $10 \mu \mathrm{g} / \mathrm{ml}$, respectively. The replicate experiments clearly show that $8701-\mathrm{BC}$ cells were responsive to extracellular decorin in a dose-dependent way. At day 7 (i.e., after 3 days of treatment) the number of cells exposed to $5 \mu \mathrm{g} / \mathrm{ml}$ of decorin showed a $25 \%$ decrease versus the untreated controls, cells treated with $7.5 \mu \mathrm{g} / \mathrm{ml}$ a decrease of $41 \%$, and cells treated with $10 \mu \mathrm{g} / \mathrm{ml}$ a decrease of $56 \%$. For each concentration we performed four replicates. These results are in good agreement with results reported by other researchers on different cell lines $[22,24]$.

\section{Morphological Assays}

Neoplastic cells, both in vivo and in vitro, display loss of adhesion and anarchic growth, often correlated with extensive membrane protrusions and vesiculation. To verify if ectopic decorin could reverse or restrain these surface perturbations, we performed morphological analyses of both transfected and parental cell cultures by scanning electron microscope. The images in Figure 3A clearly show the tremendous surface ruffling and membrane shedding of 8701-BC cells, opposite to a more regular outline of the transfected cells, both DECC2 (Figure 3B) and DEC-C3 (Figure 3C). These results indicate that decorin definitely restrains these aggressive-type surface activities, reverting the cell morphology toward a more differentiated phenotype.

\section{Effect on 8701-BC Proteomic Expression Profiles}

Figure $4 \mathrm{~A}$ shows a representative proteomic map of the parental 8701-BC cells, where the protein identities are marked with labels corresponding to the abbreviated name of the Swiss-Prot database. The number of protein spots in the map is 130 corresponding to 78 genes. When present, the different isoelectric forms of a protein are indicated with alphabetical letters, starting with "a" at the more acidic $\mathrm{p} I$.

Figures $4 \mathrm{~B}$ and $4 \mathrm{C}$ show the miniature of representative 2D gels from DEC-C2 and DEC-C3 cultures, respectively. The identified proteins were grouped into 6 functional categories, according to our previously described criteria [28]. In detail, present categories are the followings: 1) cytoskeleton and associated proteins, 2) metabolic enzymes, 3) molecular chaperones/heat shock proteins, 4) membrane-associated and calcium binding proteins, 5) detoxification, degradation, and related proteins, and 6) biosynthesis and proliferation regulators.

A detailed description of comparative proteomic profiles of DEC-C2 and DEC-C3 clones versus the parental 8701-BC cells is given for each protein category in the histograms in Figure 5. Each value is the average of three different gels. For graphical limitations the SD values (5-10\%) were not included in figures.
According to general criteria for gene expression amplitude, the degree of the modulation was considered high $\left({ }^{* *}\right)$ for fold values $\geq 2$ and medium $\left(^{*}\right)$ for values between 2.0 and 1.5.

\section{Cytoskeleton and Associated Proteins}

In this group we identified 28 protein spots corresponding to 12 different proteins (Figure 5A), 5 of which are structural proteins, actin (ACT, 6 isoforms), cytokeratin 9 (K1C9), tubulin alpha-1 (TBA1, 3 isoforms), tubulin beta-5 (TBB5, 3 isoforms), and vimentin (VIME, 5 isoforms). The others correspond to actin-binding proteins: myosin light polypeptide 6 (MYL6), cofilin (COF1, 2 isoforms), profilin 1 (PROF1, 2 isoforms), ezrin (EZRI), tropomyosin beta (TPM2), tropomyosin alpha 4 (TPM4, 2 isoforms), and thymosin beta 4 (TYB4). We found that structural proteins show modest modulation in the transfected clones, whereas a higher degree of modulation was observed in the subgroup of actin-binding proteins, which play pivotal roles in the cytoskeleton reorganization. Among these, the decrease of acidic forms of cofilin and profilin, and an increase of tropomyosin and thymosin beta 4 , were detected.

\section{Metabolic Enzymes}

Within this group of proteins we identified so far 27 spots, corresponding to 16 different enzymes and isoforms (Figure $5 \mathrm{~B})$. Four of them correspond to the following mitochondrial enzymes: aconitase (ACON), ATP synthase beta chain (ATPB), cytochrome c oxidase polypeptide Va (COX5A), and malate dehydrogenase (MDHM, 2 isoforms). Conversely, the majority of protein spots belong to the anaerobic glycolytic pathway, namely: fructose-biphosphate aldolase A (ALDOA, 2 isoforms), enolase alpha (ENOA, 3 isoforms), glyceraldehyde-3-phosphate dehydrogenase (G3P2, 5 isoforms), phosphoglycerate kinase 1 (PGK1, 2 isoforms), phosphoglycerate mutase 1(PGAM1), pyruvate kinase (KPYM, 2 isoforms), triosephosphate isomerase (TPIS, 2 isoforms), and the final step-enzyme of the anaerobic glycolysis the 1-lactate dehydrogenase (LDH A and B chains). A collective lowered expression $(\sim 1.5 / 2$ fold $)$ of glycolytic enzymes and significant increase of COX5A were detected in both clones versus the parental cells. The other proteins identified in this group are acyl-CoA dehydrogenase (ACADS), retinal dehydrogenase 1 (AL1A1), and enoyl-CoA hydratase (ECHM). ACADS was not detected in DEC-C2 and DEC-C3 clones, while the others did not show significant variations.

\section{Molecular Chaperones/Heat Shock Proteins}

In this group we have at present catalogued 25 protein spots corresponding to 15 distinct proteins (Figure 5C). Some of them belong to the classical heat shock protein families, namely: 94 $\mathrm{kDa}$ glucose-regulated protein (GRP94, 2 isoforms); several components of the Hsp 70 family, i.e., $78 \mathrm{kDa}$ glucose-regulated protein (GRP78, 3 isoforms), $75 \mathrm{kDa}$ glucose regulated protein 


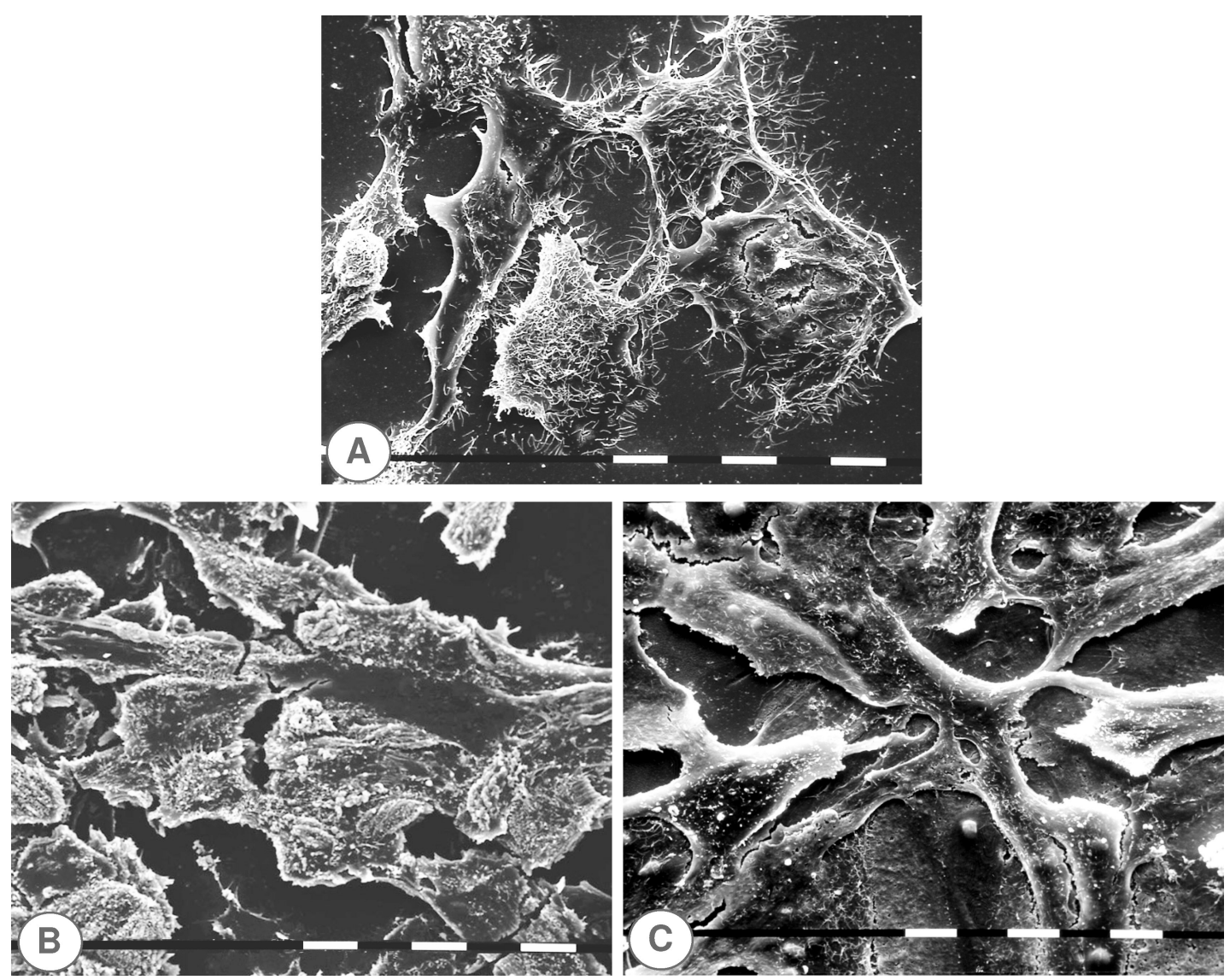

FIG. 3. Scanning electron micrographs of (A) 8701-BC parental cell line, (B) DEC-C2 transfected clone, and (C) DEC-C3 transfected clone. (magnification:1000X).

(GRP75), heat shock $70 \mathrm{kDa}$ protein 1 (HSP71), heat shock $70 \mathrm{kDa}$ protein 4 (HSP74), heat shock cognate $71 \mathrm{kDa}$ protein (HSP7C, 2 isoforms); 3 isoforms of the chaperonin HSP60 and 2 isoforms of HSP27, a member of the small heat shock proteins.

Other proteins included in this category display additional activities related to different part of the molecules. Among these proteins are the calreticulin (CRTC), 2 isoforms of the protein disulfide isomerase $\mathrm{A} 3$ (PDIA3), the protein disulfide isomerase A1 (PDIA1), 3 isoforms of the peptidyl-prolyl cis-trans isomerase A (PPIA), the transitional endoplasmic reticulum ATPase (TERA), and two chaperonines (TCTP and TCPZ) involved in microtubule-stabilization and in the folding of actin and tubulin. Significant variations within this category were the increase of GRP94, HSP74, PDIA1, TCTP, the acidic form of GRP78, and PPIA.

\section{Membrane-Associated and Calcium-Binding Proteins}

This group of proteins contains 19 spots corresponding to 10 distinct proteins (Figure 5D), belonging to the families of annexins (2 isoforms of ANXA1, 2 isoforms of ANXA2, 2 isoforms of ANXA4 plus 3 short forms), galectins (LEG1 and 2 isoforms of LEG3), S100 calcium-binding (S10A4, S10AB,
2 isoforms of S10A6), calmodulin (CALM), and 2 isofoms of voltage-dependent anion-selective channel protein 1(VDAC1). A considerable modulation was detected for annexin 4, showing an increase of its levels either in DEC-C2 and DEC-C3, and for annexin 2, whose levels decrease in transfected cells. Among the Ca-binding proteins we observed a significant increase of calmodulin levels in DEC-C2 and DEC-C3. Calmodulin-Ca ${ }^{++}$ ions interaction stimulates a wide number of enzymatic proteins and overall kinases and phosphatases involved in intracellular signalling, cytoskeletal organization, and cell cycle control. Conversely, a net decrease of S100A4 in DEC-C2 cells and its absence in DEC-C3 were observed.

\section{Detoxification, Degradation and Related Proteins}

In this category we identified 20 protein spots corresponding to 14 distinct proteins (Figure 5E). Nine belong to the detox pathways: aldo-keto reductase family 1 (AK1C3 and 2 isoforms of AK1BA), aldose reductase (ALDR, 2 isoforms), glutathione S-transferase P (GSTP1), peroxiredoxin 1 and 6 (PRDX1, 3 isoforms, and PRDX6), superoxide dismutase $[\mathrm{Cu}-\mathrm{Zn}]$ and $[\mathrm{Mn}]$ (SODC and SODM, 2 isoforms), thioredoxin (THIO, 2 isoforms) and a thioredoxin-related protein, $\mathrm{SH} 3$ 

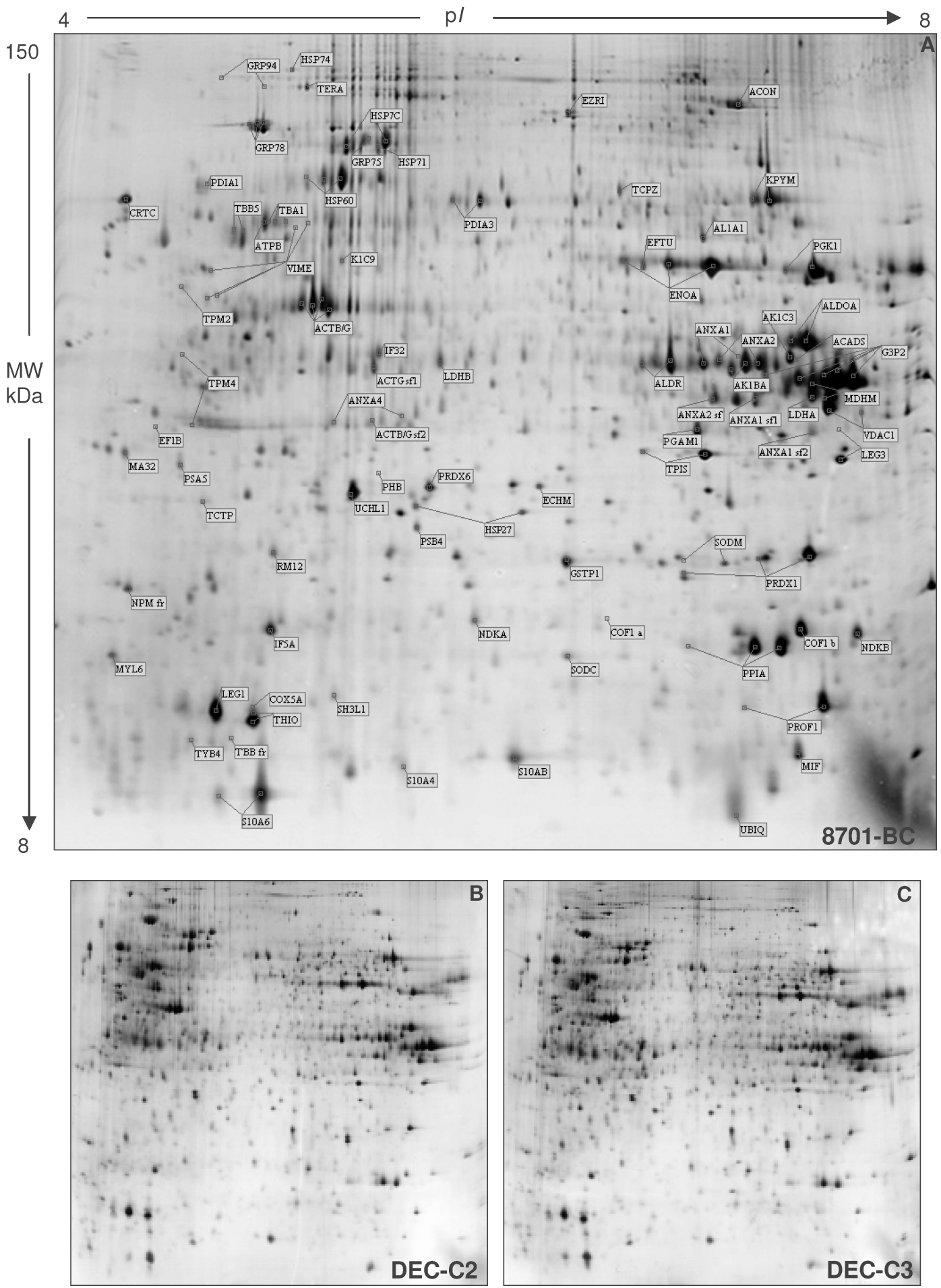

FIG. 4. Representative proteomic maps of 8701-BC parental cell line (A). Protein spots of known identity are labelled with the abbreviated name of the Swiss-Prot database. When present, different isoforms of the same protein are jointly labelled. Other abbreviation: $s f=$ short form. (B) and (C) show the miniature maps of DEC-C2 and DEC-C3 transfected clones respectively. 

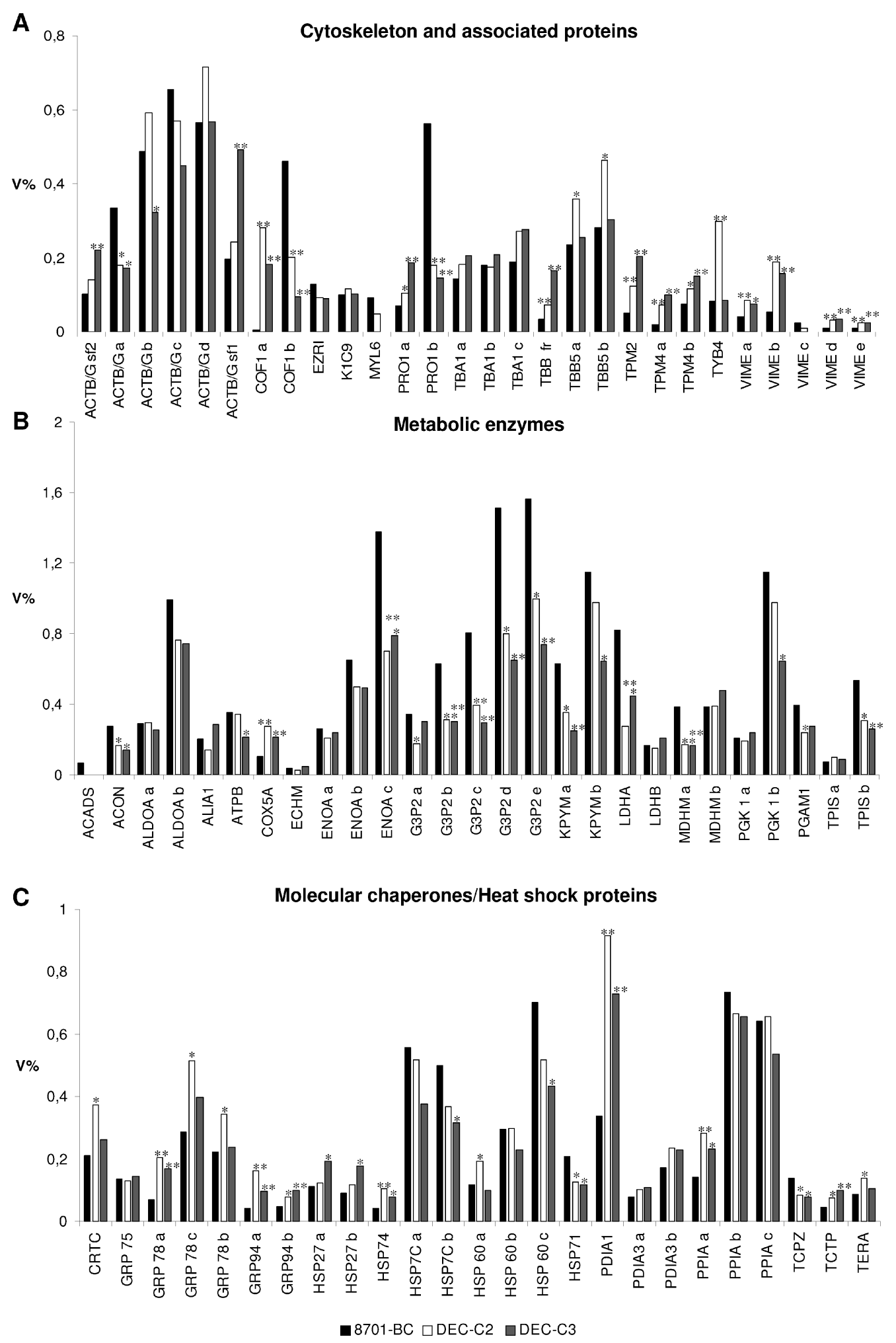

FIG. 5. Histograms of differentially expressed proteins in 8701-BC cells and in the two selected clones. Relative intensity of protein spots was calculated normalizing the data to the sum of all spot volumes on gels (vol\%). Each value is the mean of three independent determinations. For graphical limitations the SD values (5-10\%) were not included in figures. According to general criteria for gene expression amplitude, the degree of the modulation was considered high $\left({ }^{* *}\right)$ for fold values $\geq 2$ and medium $\left({ }^{*}\right)$ for values between 2.0 and 1.5. Protein clusters (A) cytoskeleton and associated proteins, (B) metabolic enzymes, (C) molecular chaperones/heat shock proteins, (D) membrane-associated and calcium binding proteins, (E) detoxification, degradation and related proteins, and (F) biosynthesis and proliferation regulators. 
D

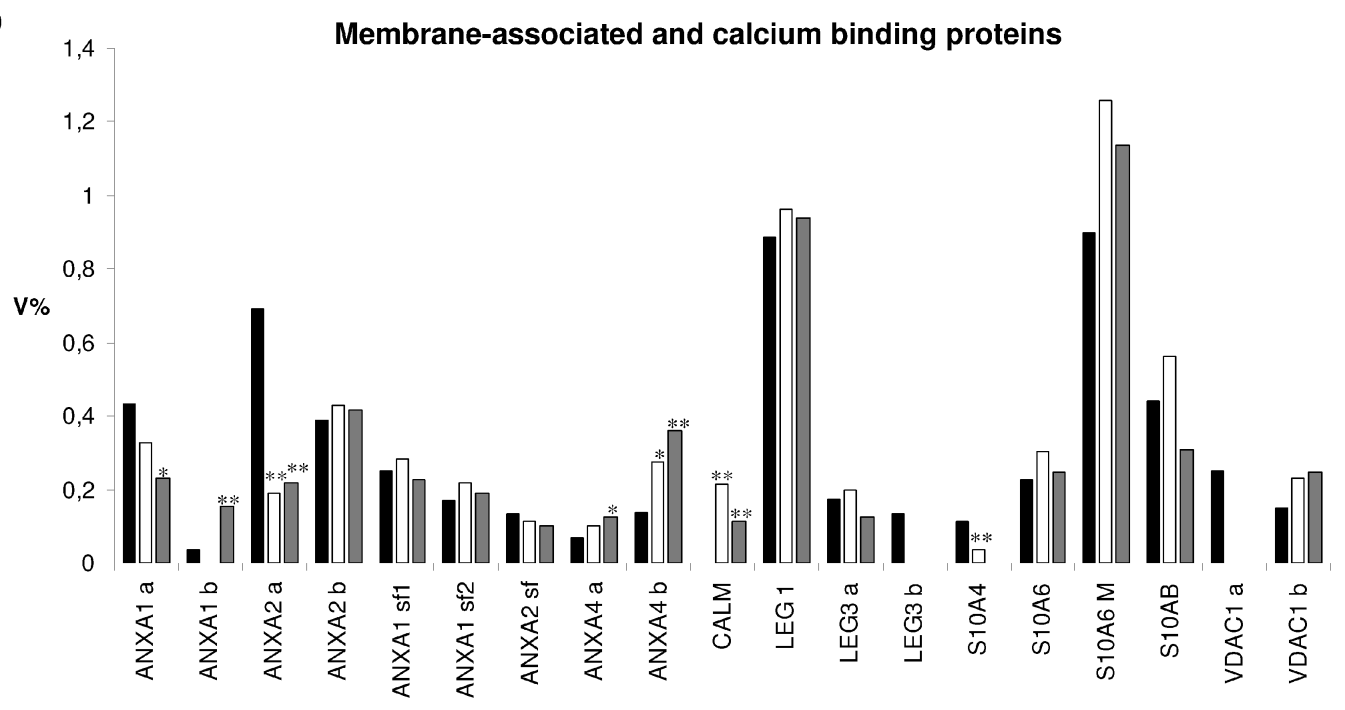

$\mathbf{E}$

Detoxification, degradation and related proteins

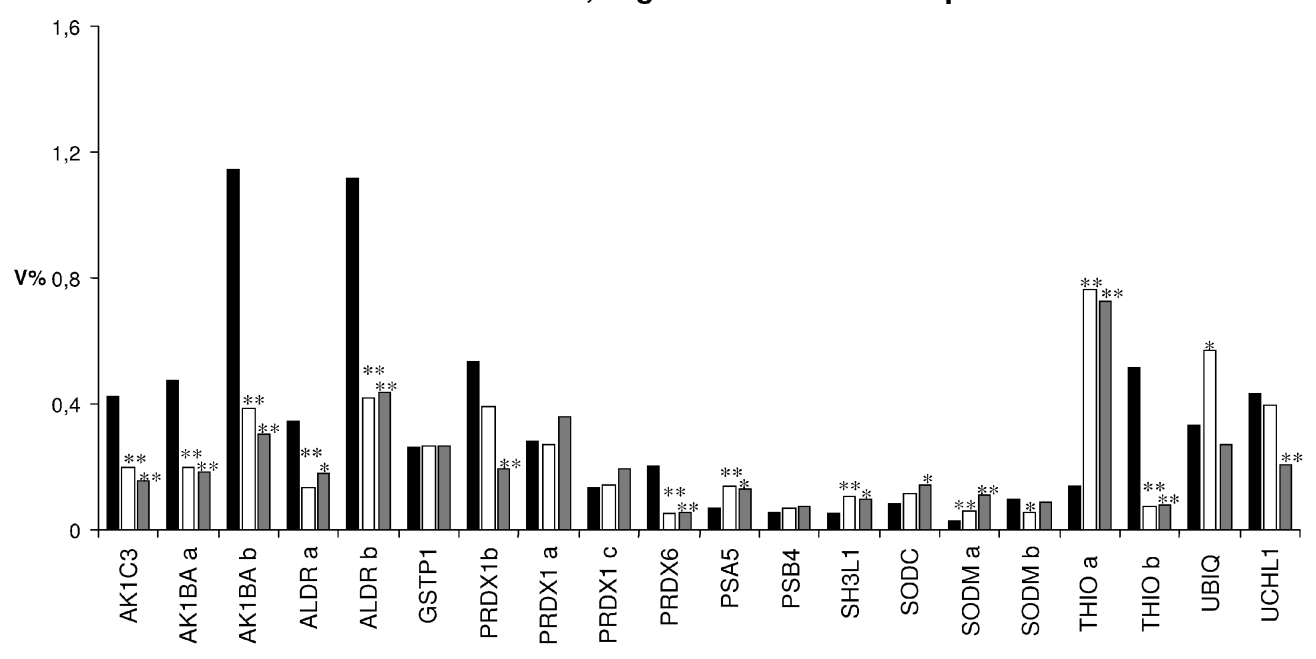

$\mathbf{F}$

Biosynthesis and proliferation regulators

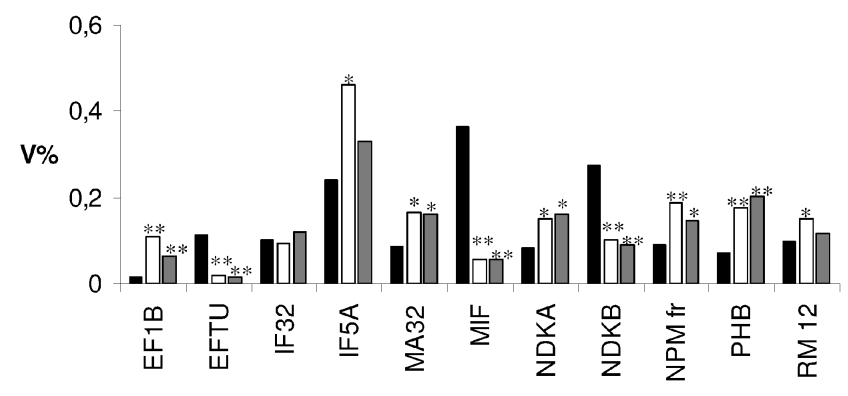

- 8701-BC $\square$ DEC-C2 $\square$ DEC-C3

FIG. 5. (Continued). 
domain-binding glutamic acid-rich-like protein (SH3L1). The degradation pathway includes the following proteins: proteasome subunits alpha type 5 and beta type 4 (PSA5, PSB4), ubiquitin (UBIQ), and the ubiquitin carboxyl-terminal hydrolase isozyme L1 (UCHL1). Five proteins of the redox pathway, AK1C3, AK1BA and ALDR, PRDX6, and 1 isoform of THIO, are drastically reduced in both DEC-C2 and DEC-C3. Other proteins of both detox and degradation pathways undergo little changes, while a net increment was observed for the PSA5, 1 isoform of SODM and THIO and for the SH3L1, a putative modulator of the redox function [34].

\section{Biosynthesis, Cell Growth and Proliferation Regulators}

Although proteins belonging to these categories are produced in rather small amounts, in the present group we detected 10 proteins and 1 protein fragment (Figure 5F): translation initiation factors IF5A and IF32, the translation elongation factors 1-beta (EF1B) and EFTU (mitochondrial), the nucleoside diphosphate kinase $\mathrm{A}$ and $\mathrm{B}$ (NDKA, NDKB), the ribosomal protein L12 (RM12), the hyaluronan-binding protein 1 (MA32/C1QBP), the macrophage migration inhibitory factor (MIF), and the prohibitin (PHB). In particular, 2 of these proteins, MIF, a pleiotropic factor promoting neoplastic cell proliferation [35], and the prohibitin, a negatively controller of the cell cycle [36], showed significant modulations. Interestingly, a net decrease ( 5-fold) of MIF levels was observed in both DEC-C2 and DEC-C3 cells versus the parental cells, contrary to the net increase of PHB.

\section{DISCUSSION}

The literature of the past 10 years has produced a great deal of data concerning the involvement of decorin in cancer. To our knowledge, the present report is likely the first study focusing on wide-ranged responses induced by the ectopic expression of decorin in breast cancer cells. As an in vitro model we utilized the breast cancer cell line 8701-BC and 2 decorin-transfected clones: DEC-C2, expressing and producing the full decorin proteoglycan, and DEC-C3, producing only the protein core.

Introductory results obtained by cell proliferation assays showed a remarkable antiproliferative effect of decorin, when either exogenously added or endogenously produced by a transgene. These results, in agreement with other relevant studies by other authors, suggest a general mode of action of decorin, acting from the outside of the cells, either in other breast cell culture (MCF7) or in cell cultures of various histological origin [24].

It is known that neoplastic cells are characterized by abnormal growth, not only because they are more accelerated than normal counterparts, but also for the anarchical cell-cell interactions, due to the loss of cell adhesion and the emergence of spikes, lamellipodia, and other membrane ruffling. All these perturbations, which are distinctly produced by the parental breast cancer cells 8701-BC, were definitely restrained in the decorin-transfected clones.

To investigate wide-ranged effects of transgenic decorin we performed comparative proteomic analyses on parental and transfected cells. The obtained data demonstrated that ectopic decorin, both as proteoglycan and protein core, induces significant modulation within the protein categories identified in our experimental system. Within the category of cytoskeleton and associated proteins, cofilin, profilin, and tropomyosin beta, were the most responsive to the ectopic decorin in both clones.

Cofilin and profilin are involved directly in actin polimerization: in both transfected clones we observed a net decrease of the basic forms of cofilin and profilin and the correspective increase of the acidic forms. The latter, on the basis of isoelectric point"estimator"/ calculator (http://www.nihilnovus.com/ Palabra.html), may correspond to the phosphorylated isoforms. This result is well correlated with the regression of lamellipodia and other membrane protrusion in the transfected clones versus the parental 8701-BC cells.

Conversely, tropomyosin (3 isoforms) was more expressed in both DEC-C2 and DEC-C3 clones, suggesting that the recovery of more differentiated features of transfected cells also may be mediated by restored levels of tropomyosin. Other authors have reported that tropomyosin is downregulated in breast carcinoma cells [37] that the forced expression of several isoforms of tropomyosin in cancer cells can suppress their growth or induce a more differentiated cellular morphology [38, 39]. Related to cytoskeleton and surface activities are several members of the annexin family, a class of calcium- and phospholipid-binding proteins that associate reversibly with membranes, so acting as scaffolding or bridging proteins [40, for review]. Several members of this family have been related to cancer progression [41-43].

Our results show an opposite modulation of ANXA2 (positive) and ANXA4 (negative) for which we have no explanation at present, however this is the first report showing a correlation between decorin actions and annexin expression levels. It is noteworthy to observe that the other protein category responsive to the ectopic decorin is that of glycolytic enzymes, which appeared collectively decreased in both transfected clones, by an average value of 1.5-2 fold relative intensity.

It is well-known that the tumoral cells have an altered metabolic pattern. In particular an increment of the anaerobic metabolism of the glucose has been observed in the presence of physiological oxygen levels. This phenomenon, known as Warburg effect, so named after its discovery [44], seems to be a common phenomenon in the development of the solid tumors, or in the acquisition of the invasive ability by neoplastic cells. More recently, magnetic-resonance spectroscopy and positron-emission tomography studies with 18F-fluoro-deoxyglucose have consistently demonstrated that cancer patients show elevated levels of glucose uptake with respect to normal subjects [45]. 
Current opinion states that these metabolic changes associated with malignant tumors are not primarily related to cancer etiology, but they may confer a common advantage on neoplastic cells in their survival and invasion of surrounding connective tissues under conditions of low oxygen supply. This suggests that metabolic alterations in cancer may be due to long-term gene deregulation associated with some early step of oncogenic transformation. This hypothesis is further supported by some preliminary data from our lab indicating a concomitant decorinassociated mRNA downregulation of two key oncogenes in breast cancer, c-Myc and c-erbB2 (data not shown). Indeed both oncogenes are the most commonly amplified oncogenes in human breast cancer $[46,47]$ and are involved in the direct or indirect activation of numerous genes, among which ENOA and PGK1 [48, 49], as well as MIF andVDAC1 [50], IF5A [51], HZP27 [49], which we found decreased in both DEC-C2 and DEC-C3 clones.

Additionally, decorin appears to downregulate the production of several putative breast cancer biomarkers. Of particular interest was the observed net decrease of S100A4 in DEC-C2 cells and its absence in DEC-C3. The S100A4 (also referred to as metastasin, calvasculin, or placental calcium-binding protein) belongs to the S100-family of proteins and has been found to stimulate metastatic spread of tumor cells in association with enhanced expression of the invasivity marker uPA [52]. Moreover elevated expression of S100A4 is correlated with poor prognosis in many human cancers [53]. Its net decrease, or abrogation, following decorin is of primary interest, given the postulated action of decorin as an antioncogenic molecule.

The effects of decorin were also associated with opposing changes in the expression levels of two modulators of cell cycle: MIF and prohibitin. MIF is a pleiotropic factor and found frequently overexpressed in primary breast cancers, where it also has functionally inactivated the p53 tumor suppressor and inhibited p53-responsive gene expression and apoptosis [54]. Interestingly, our results show a significant decrease of MIF levels, both in DEC-C2 and DEC-C3 cells. Conversely, prohibitin known to be a negative regulator of cell proliferation and a putative tumor suppressor, shows a significant increase in decorin-transfected cells.

Concurrently, decorin appears to drastically reduce the expression levels of several proteins involved in detoxification pathway, both DEC-C2 and DEC-C3, without extensively affecting the category of heat shock proteins, which are involved in many stress responses. Members of the detoxification aldoketo reductase family and aldose reductase have been associated with cancer and are believed to be involved in drug resistance [55-57]. It is of great interest that the decorin induces a decrease of these protein expression, concominat with the increment of the SH3 domain-binding glutamic acid-rich-like protein $(\mathrm{SH} 3 \mathrm{~L} 1)$ a putative modulator of the redox function and structurally reconducted to thioredoxin super family [34].

\section{CONCLUSION}

The results of the present study revealed new important antioncogenic potentialities exerted by decorin, either as a proteoglycan or as a protein core, through a variety of distinct biochemical pathways, probably involved in the reversion of the malignat features of the 8701-BC phenotype toward a more differentiate state. Major decorin effects include the reduction of proliferation rate, hyper glycolytic phenotype, exaggerate membrane ruffling, lamellipodia formation and vesiculation, and the poor cell-cell adhesiveness. Concurrently, the expression of ectopic decorin is associated with a net decrease of several potential breast cancer biomarkers. Moreover, decorin seems to downregulate the expression of c-Myc and c-erbB2, which in turn may contribute to the phenotype reprogramming.

Taken together, these results provide new important elements in support of the potential antioncogenic role exerted by decorin, disclosing original aspects related to the reversion of malignant traits of a prototype of breast cancer cells, and raise additional interest for the postulated clinical application of decorin. At the same time, the proteomic approach, while disclosing new putative pathways for the decorin action, presented unexpected responses concerning a number of proteins, which deserve future investigations.

\section{ACKNOWLEDGMENTS}

The present research was supported in part by a MIUR grant "Prin-prot. 2001054958_001" and in part by Por Sicilia (misura 3.14 project DIAMOL).

\section{REFERENCES}

1. Van Den Hooff, A. (1988). Stromal involvement in malignant growth. $A d v$. Cancer Res., 50, 159-196.

2. Schor, S. L., and Schor, A. M. (2001). Phenotypic and genetic alterations in mammary stroma: implications for tumour progression. Breast Cancer Res., 3, 373-379.

3. Hansen, R. K., and Bissell, M. (2000). Tissue architecture and breast cancer: the role of extracellular matrix and steroid hormones. Endocr. Relat. Cancer, 7, 95-113.

4. Liotta, L.A., and Kohn, E.C. (2001). The microenvironment of the tumourhost interface. Nature, 411, 375-379.

5. Pucci-Minafra, I., Minafra, S., Tomasino, R.M., Sciarrino, S., and Tinervia, R. (1986). Collagen changes in the ductal infiltrating (scirrhous) carcinoma of the human breast. A possible role played by type I trimer collagen on the invasive growth. J. Submicrosc. Cytol., 4, 795-805.

6. Pucci-Minafra, I., Luparello, C., Andriolo, M., Basiricò, L., Aquino, A., and Minafra, S. (1993). A new form of tumor and fetal collagen that binds laminin. Biochemistry, 29, 7421-7427.

7. Fernandez, M., Keyrilainen, J., Serimaa, R., Torkkeli, M., KarjalainenLindsberg, M.L., Tenhunen, M., Thomlinson, W., Urban, V., and Suortti, P. (2002). Small-angle x-ray scattering studies of human breast tissue samples. Phys. Med. Biol., 47, 577-592.

8. Minafra, S., Giambelluca, C., Andriolo, M., and Pucci-Minafra, I. (1995). Cell-cell and cell-collagen interactions influence gelatinase production by human breast-carcinoma cell line 8701-BC. Int. J. Cancer, 62, 777783.

9. Iozzo, R.V. (1998). Matrix proteoglycans: from molecular design to cellular function. Ann. Rev. Biochem., 67, 609-652. 
10. Krusius, T., and Ruoslahti, E. (1986). Primary structure of an extracellular matrix proteoglycan core protein deduced from cloned cDNA. Proc. Natl. Acad. Sci. USA, 20, 7683-7687.

11. Hocking, A.M., Shinomura, T., and McQuillan, D.J. (1998). Leucine-rich repeat glycoproteins of the extracellular matrix. Matrix Biol., 17, 1-19.

12. Ameye, L., and Young, M.F. (2002). Mice deficient in small leucine-rich proteoglycans: novel in vivo models for osteoporosis, osteoarthritis, EhlersDanlos syndrome, muscular dystrophy, and corneal diseases. Glycobiology, $12,107 \mathrm{R}-116 \mathrm{R}$.

13. Reed, C.C., and Iozzo, R.V. (2002). The role of decorin in collagen fibrillogenesis and skin homeostasis. Glycoconj. J., 19, 249-255.

14. Bidanset, D.J., Guidry, C., Rosenberg, L.C., Choi, H.U., Timpl, R., and Hook, M. (1992). Binding of the proteoglycan decorin to collagen type VI. J. Biol. Chem., 267, 5250-5256.

15. Font, B., Aubert-Foucher, E., Goldschmidt, D., Eichenberger, D., and Van Der Rest, M. (1993). Binding of collagen XIV with the dermatan sulfate side chain of decorin. J. Biol. Chem., 268, 25015-25018.

16. Font, B., Eichenberger, D., Rosenberg, L.M., and Van Der Rest, M. (1996). Characterization of the interactions of type XII collagen with two small proteoglycans from fetal bovine tendon, decorin and fibromodulin. Matrix Biol., 15, 341-348.

17. Schmidt, G., Robenek, H., Harrach, B., Glossl, J., Nolte, V., Hormann, H., Richter, H., and Kresse, H. (1987). Interaction of small dermatan sulfate proteoglycan from fibroblasts with fibronectin. J. Cell Biol., 104, 16831691.

18. Winnemoller, M., Schon, P., Vischer, P., and Kresse, H. (1992). Interactions between thrombospondin and the small proteoglycan decorin: interference with cell attachment. Eur. J. Cell. Biol., 59, 47-55.

19. Krumdieck, R., Hook, M., Rosenberg, L.C., and Volanakis, J.E. (1992). The proteoglycan decorin binds $\mathrm{C} 1 \mathrm{q}$ and inhibits the activity of the $\mathrm{C} 1$ complex. J. Immunol., 149, 3695-3701.

20. Iozzo, R.V., Moscatello, D.K., McQuillan, D.J., and Eichstetter, I. (1999). Decorin is a biological ligand for the epidermal growth factor receptor. J. Biol. Chem., 274, 4489-4492.

21. De Luca, A., Santra, M., Baldi, A., Giordano, A., and Iozzo, R.V. (1996). Decorin-induced growth suppression is associated with up-regulation of p21, an inhibitor of cyclin-dependent kinases. J. Bio.l Chem., 271, 1896118965.

22. Santra, M., Skorski, T., Calabretta, B., Lattime, E.C., and Iozzo, R.V. (1995). De novo decorin gene expression suppresses the malignant phenotype in human colon cancer cells. Proc. Natl. Acad. Sci. USA, 92, 7016-7020.

23. Moscatello, D.K., Santa, M., Mann, D.M., McQuillan, D.J., Wong, A.J., and Iozzo, R.V. (1998). Decorin suppresses tumor cell growth by activating the epidermal growth factor receptor. J. Clin. Invest., 101, 406-412.

24. Santra, M., Mann, D.M., Mercer, E.W., Skorski, T., Calabretta, B., and Iozzo, R.V. (1997). Ectopic expression of decorin protein core causes a generalized growth suppression in neoplastic cells of various histogenetic origin and requires endogenous p21, an inhibitor of cyclin-dependent kinases. J. Clin. Invest., 100, 149-57.

25. Minafra, S., Morello, V., Glorioso, F., Tomasino, R.M., Feo, S., McIntosh, D., and Woolley, D.E. (1989). A new cell line (8701-BC) from primary ductal infiltrating carcinoma of human breast. Br. J. Cancer., 60, 185192.

26. Pucci-Minafra, I., Fontana, S., Cancemi, P., Alaimo, G., and Minafra, S. (2002). Proteomic patterns of cultured breast cancer cells and epithelial mammary cells. Ann. NY Acad. Sci., 963, 122-139.

27. Pucci-Minafra, I., Fontana, S., Cancemi, P., Basiricò, L., Caricato, S., and Minafra, S. (2002). A contribution to breast cancer cell proteomics: detection of new sequences. Proteomics, 2, 919-927.

28. Pucci-Minafra, I., Cancemi, P., Fontana, S., Minafra, L., Feo, S., Becchi, M., Freyria, A.M., and Minafra, S. (2006). Expanding the protein catalogue in the proteome reference map of human breast cancer cells. Proteomics, $6,2609-2625$
29. Tenni, R., Viola, M., Welser, F., Sini, P., Giudici, C., Rossi, A., and Tira, M.E. (2002). Interaction of decorin with $\mathrm{CNBr}$ peptides from collagens I and II. Evidence for multiple binding sites and essential lysyl residues in collagen. Eur. J. Biochem., 269, 1428-1437.

30. Bradford, M.M. (1976). A rapid and sensitive method for the quantitation of microgram quantities of protein utilizing the principle of protein-dye binding. Anal. Biochem., 72, 248-254.

31. Fontana, S., Pucci-Minafra, I., Becchi, M., Freyria, A.M., and Minafra, S. (2004). Effect of collagen substrates on proteomic modulation of breast cancer cells. Proteomics, 4, 849-860.

32. Chang, J., Van Remmen, H., Ward, W.F., Regnier, F.E., Richardson, A., and Cornell, J. (2004). Processing of data generated by 2-dimensional gel electrophoresis for statistical analysis: missing data, normalization, and statistics. J. Proteome Res., 3, 1210-1218.

33. Wheelock, A.M., and Goto, S. (2006). Effects of post-electrophoretic analysis on variance in gel-based proteomics. Expert Rev. Proteomics, 3, 129-142.

34. Cardini, M., Mazzocco, M., Massaro, A., Maffei, M., Vergano, A., Donadini, A., Scartezzini, P., and Bolognesi, M. (2004). Crystal structure of the glutaredoxin-like protein SH3BGRL3 at 1.6 Angstrom resolution. Biochem. Biophys. Res. Commun., 318, 470-476.

35. Swant, J.D., Rendon, B.E., Symons, M., and Mitchell, R.A. (2005). Rho GTPase-dependent signaling is required for macrophage migration inhibitory factor-mediated expression of cyclin D1. J. Biol. Chem., 280, 23066-23072.

36. Nadimpalli, R., Yalpani, N., Johal, G.S., and Simmons, C.R. (2000). Prohibitins, stomatins, and plant disease response genes compose a protein superfamily that controls cell proliferation, ion channel regulation, and death. J. Biol. Chem., 275, 29579-29586.

37. Franzen, B., Linder, S., Uryu, K., Alaiya, A.A., Hirano, T., Kato, H., and Auer, G. (1996). Expression of tropomyosin isoforms in benign and malignant human breast lesions. Br. J. Cancer, 73, 909-913.

38. Prasad, G.L., Fuldner, R.A., and Cooper, H.L. (1993). Expression of transduced tropomyosin $1 \mathrm{cDNA}$ suppresses neoplastic growth of cells transformed by the ras oncogene. Proc. Natl. Acad. Sci. USA, 90, 70397043.

39. Mahadev, K., Raval, G., Bharadwaj, S., Willingham, M.C., Lange, E.M., Vonderhaar, B., Salomon, D., and Prasad, G.L. (2002). Suppression of the transformed phenotype of breast cancer by tropomyosin-1. Exp. Cell. Res., $279,40-51$.

40. Gerke, V., and Moss, S.E. (2002). Annexins: from structure to function. Physiol Rev., 82, 331-371.

41. Wu, W., Tang, X., Hu, W., Lotan, R., Hong, W.K., and Mao, L. (2002). Identification and validation of metastasis-associated proteins in head and neck cancer cell lines by two-dimensional electrophoresis and mass spectrometry. Clin. Exp. Metastasis., 19, 319-326.

42. Koike, H., Uzawa, K., Nakashima, D., Shimada, K., Kato, Y., Higo, M., Kouzu, Y., Endo, Y., Kasamatsu, A., and Tanzawa, H. (2005). Identification of differentially expressed proteins in oral squamous cell carcinoma using a global proteomic approach. Int. J. Oncol., 27, 59-67.

43. Alfonso, P., Nunez, A., Madoz-Gurpide, J., Lombardia, L., Sanchez, L., and Casal, J.I. (2005). Proteomic expression analysis of colorectal cancer by two-dimensional differential gel electrophoresis. Proteomics., 5, 26022611.

44. Warburg, O. (1930). The Metabolism of Tumours. Arnold Constable: London.

45. Port, E.R., Yeung, H., Gonen, M., Liberman, L., Caravelli, J., Borgen, P., and Larson, S. (2006). 18F-2-fluoro-2-deoxy-D-glucose positron emission tomography scanning affects surgical management in selected patients with high-risk, operable breast carcinoma. Ann. Surg. Oncol., 13, 677-684.

46. Blancato, J., Singh, B., Liu, A., Liao, D.J., and Dickson, R.B. (2004). Correlation of amplification and overexpression of the c-myc oncogene in high-grade breast cancer: FISH, in situ hybridisation and immunohistochemical analyses. Br. J. Cancer., 90, 1612-1619. 
47. Menard, S., Casalini, P., Campiglio, M., Pupa, S.M., and Tagliabue, E. (2004). Role of HER2/neu in tumor progression and therapy. Cell. Mol. Life Sci., 61, 2965-2978.

48. Osthus, R.C., Shim, H., Kim, S., Li, Q., Reddy, R., Mukherjee, M., Xu, Y., Wonsey, D., Lee, L.A., and Dang, C.V. (2000). Deregulation of glucose transporter 1 and glycolytic gene expression by c-Myc. J. Biol. Chem., 275, 21797-21800.

49. Zhang, D., Tai, L.K., Wong, L.L., Chiu, L.L., Sethi, S.K., and Koay, E.S. (2005). Proteomic study reveals that proteins involved in metabolic and detoxification pathways are highly expressed in HER-2/neu-positive breast cancer. Mol. Cell. Proteomics., 4, 1686-1696.

50. Guo, Q.M., Malek, R.L., Kim, S., Chiao, C., He, M., Ruffy, M., Sanka, K., Lee, N.H., Dang, C.V., and Liu, E.T. (2000). Identification of c-myc responsive genes using rat cDNA microarray. Cancer Res., 60, 5922-5928.

51. Coller, H.A., Grandori, C., Tamayo, P., Colbert, T., Lander, E.S., Eisenman, R.N., and Golub, T.R. (2000). Expression analysis with oligonucleotide microarrays reveals that MYC regulates genes involved in growth, cell cycle, signaling, and adhesion. Proc. Natl. Acad. Sci. USA, 97, 32603265 .
52. Pedrocchi, M., Schafer, B.W., Mueller, H., Eppenberger, U., and Heizmann, C.W. (1994). Expression of $\mathrm{Ca}(2+)$-binding proteins of the $\mathrm{S} 100$ family in malignant human breast-cancer cell lines and biopsy samples. Int. J. Cancer, 57, 684-690.

53. Sherbet, G.V., and Lakshmi, M.S. (1998). S100A4 (MTS1) calcium binding protein in cancer growth, invasion and metastasis. Anticancer Res., 18, 2415-2421.

54. Fingerle-Rowson, G., Petrenko, O., Metz, C.N., Forsthuber, T.G., Mitchell, R., Huss, R., Moll, U., Muller, W., and Bucala, R. (2003). The p53dependent effects of macrophage migration inhibitory factor revealed by gene targeting. Proc Natl Acad Sci USA, 100, 9354-9359.

55. Jin, J., Krishack, P.A., and Cao, D. (2006). Role of aldo-keto reductases in development of prostate and breast cancer. Front Biosci., 11, 2767-2773.

56. Saraswat, M., Mrudula, T., Kumar, P.U., Suneetha, A., Rao Rao, T.S., Srinivasulu, M., and Reddy, B. (2006). Overexpression of aldose reductase in human cancer tissues. Med. Sci. Monit., 12, CR525-529.

57. Lee, K.W., Ko, B.C., Jiang, Z., Cao, D., and Chung, S.S. (2001). Overexpression of aldose reductase in liver cancers may contribute to drug resistance. Anticancer Drugs., 12, 129-132. 